\title{
Open-to-air RAFT polymerization on a surface under ambient conditions
}

Chung Soo Kim, Soojeong Cho, Ji Hoon Lee, Woo Kyung Cho, * and Kyung-sun Son*

\section{Table of Contents}

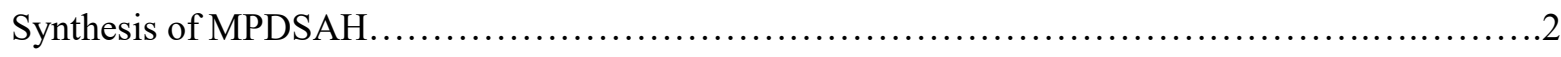

Synthesis of DDMAT-derived CTA bearing a triethoxysilane moiety..........................2

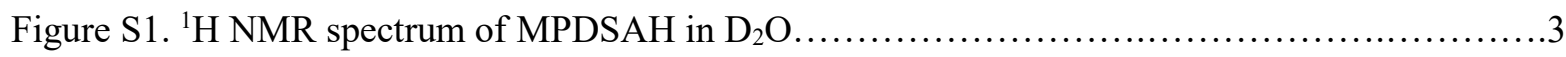

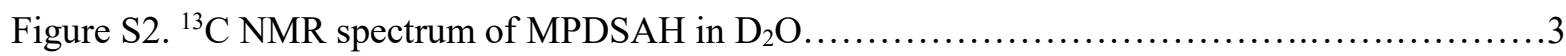

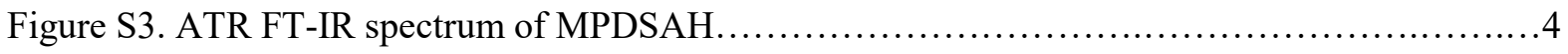

Figure S4. MALDI-TOF mass spectrum of MPDSAH....................................

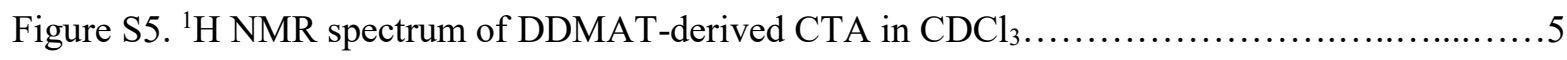

Polymer brush thickness vs. conversion vs. molecular weight $\ldots \ldots \ldots \ldots \ldots \ldots \ldots \ldots \ldots \ldots \ldots \ldots \ldots 6$

Experimental procedures for conversion and molecular weight determination......................6

Figure S6. Thickness of the PEA layer versus monomer conversion and molecular weight of "free"

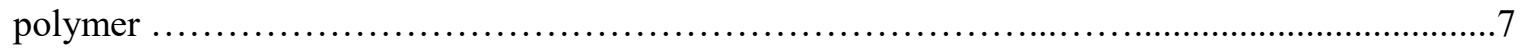

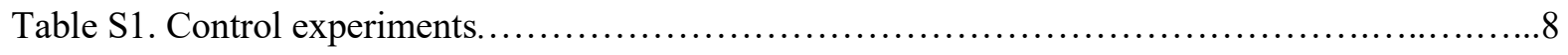

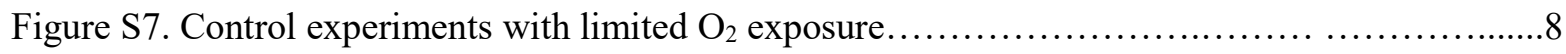

Figure S8. XPS spectra of the various polymer-coated substrates............................

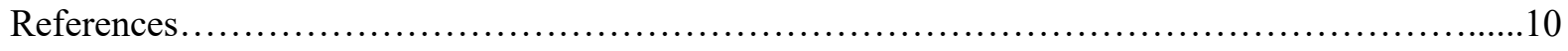




\section{Synthesis of MPDSAH.}

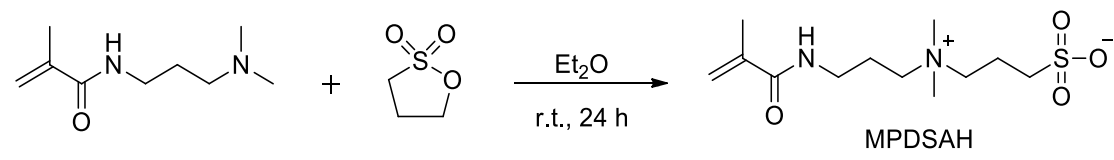

The zwitterionic monomer, MPDSAH, was synthesized using a procedure described previously. ${ }^{1}$ Diethyl ether and $\mathrm{N}$-(3-dimethylaminopropyl)methacrylamide (4.8 $\mathrm{mL}, 26.5 \mathrm{mmol}, 1 \mathrm{eq})$ were added to a roundbottomed flask. 1,3-Propanesultone $(2.3 \mathrm{~mL}, 26.2 \mathrm{mmol}, 1 \mathrm{eq})$ was added to the flask in a dropwise manner and the mixture was stirred at room temperature for 24 hours. After the reaction, the product mixture was filtered and impurities were removed by washing with acetone. The resulting white precipitate was dried under vacuum. ${ }^{1} \mathrm{H}$ NMR $\left(300 \mathrm{MHz}, \mathrm{D}_{2} \mathrm{O}\right): \delta 5.70(\mathrm{~s}, 1 \mathrm{H}), 5.46(\mathrm{~s}, 1 \mathrm{H}), 3.49-3.43(\mathrm{~m}, 2 \mathrm{H}), 3.38-3.32(\mathrm{~m}$, 4H), $3.10(\mathrm{~s}, 6 \mathrm{H}), 2.96$ (t, $J=7.2 \mathrm{~Hz}, 2 \mathrm{H}), 2.24-2.14(\mathrm{~m}, 2 \mathrm{H}), 2.08-1.98(\mathrm{~m}, 2 \mathrm{H}), 1.91(\mathrm{~s}, 3 \mathrm{H}) ;{ }^{13} \mathrm{C} \mathrm{NMR}$ (75 MHz, $\mathrm{D}_{2} \mathrm{O}$ ): $\delta 171.73,138.96,121.67,62.40,62.04,50.85,47.47,36.40,22.43,18.36,17.92$; ATR-IR (powder) $\mathrm{cm}^{-1}: 3303,2977,1656,1614,1545,1488,1189,1171,1036$; MALDI-TOF MS: $\mathrm{m} / \mathrm{z}$ calcd for $\mathrm{C}_{12} \mathrm{H}_{24} \mathrm{~N}_{2} \mathrm{O}_{4} \mathrm{~S}[\mathrm{M}]^{+}:$292.1457, found [M] 292.1530 (see Figures S1-S4).

\section{Synthesis of DDMAT-derived CTA bearing a triethoxysilane moiety.}

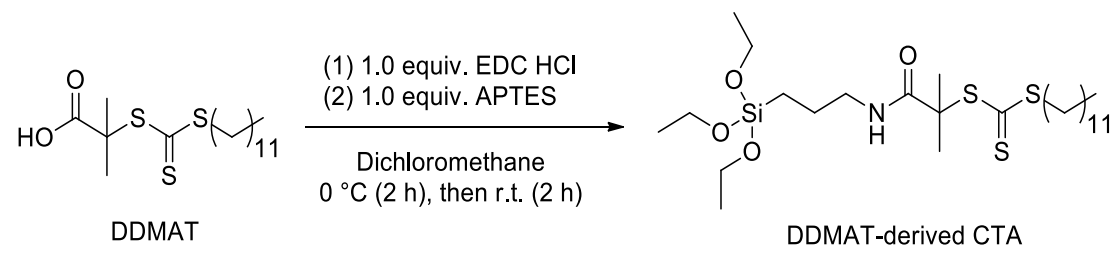

The synthesis of DDMAT-derived chain transfer agent (CTA) was performed as described previously. ${ }^{2}$ DDMAT $(0.18 \mathrm{~g}, 0.5 \mathrm{mmol}, 1 \mathrm{eq})$ was added to a $250-\mathrm{mL}$ round bottomed flask with a stirring bar and dissolved in $25 \mathrm{~mL}$ of dichloromethane. $\mathrm{EDC} \mathrm{HCl}(0.096 \mathrm{~g}, 0.5 \mathrm{mmol}, 1 \mathrm{eq})$ was added to a $20-\mathrm{mL}$ vial and dissolved in $5 \mathrm{~mL}$ of dichloromethane. $\mathrm{EDC} \mathrm{HCl}$ in dichloromethane was then added to the $250 \mathrm{~mL}$ round-bottomed flask in a dropwise manner and the solution was stirred at $0{ }^{\circ} \mathrm{C}$ for 10 minutes. Sequentially, APTES $(0.12 \mathrm{~mL}, 0.5 \mathrm{mmol}, 1 \mathrm{eq})$ was added to the flask in a dropwise manner, and the solution was then stirred at $0{ }^{\circ} \mathrm{C}$ for 2 hours. After stirring at $0{ }^{\circ} \mathrm{C}$, the solution was stirred at room temperature for 2 hours then concentrated using an evaporator. The crude product was purified by silica column chromatography $(1: 1 \mathrm{v} / \mathrm{v}$ ethyl acetate and hexane) to obtain the synthesized DDMAT-derived CTA as a viscous yellow liquid (102 mg, 35.9\%). ${ }^{1} \mathrm{H}$ NMR (600 MHz, $\left.\mathrm{CDCl}_{3}\right): 0.60$ (t, 2H), 0.89 (t, 3H), 1.23 $(\mathrm{t}, 9 \mathrm{H}), 1.26(\mathrm{~m}, 16 \mathrm{H}), 1.38(\mathrm{~m}, 2 \mathrm{H}), 1.60(\mathrm{~m}, 2 \mathrm{H}), 1.66(\mathrm{~m}, 2 \mathrm{H}), 1.70(\mathrm{~s}, 6 \mathrm{H}), 3.23(\mathrm{q}, 2 \mathrm{H}), 3.27(\mathrm{t}, 2 \mathrm{H})$, $3.81(\mathrm{q}, 6 \mathrm{H}), 6.63(\mathrm{t}, 1 \mathrm{H})$ (see Figure S5). 


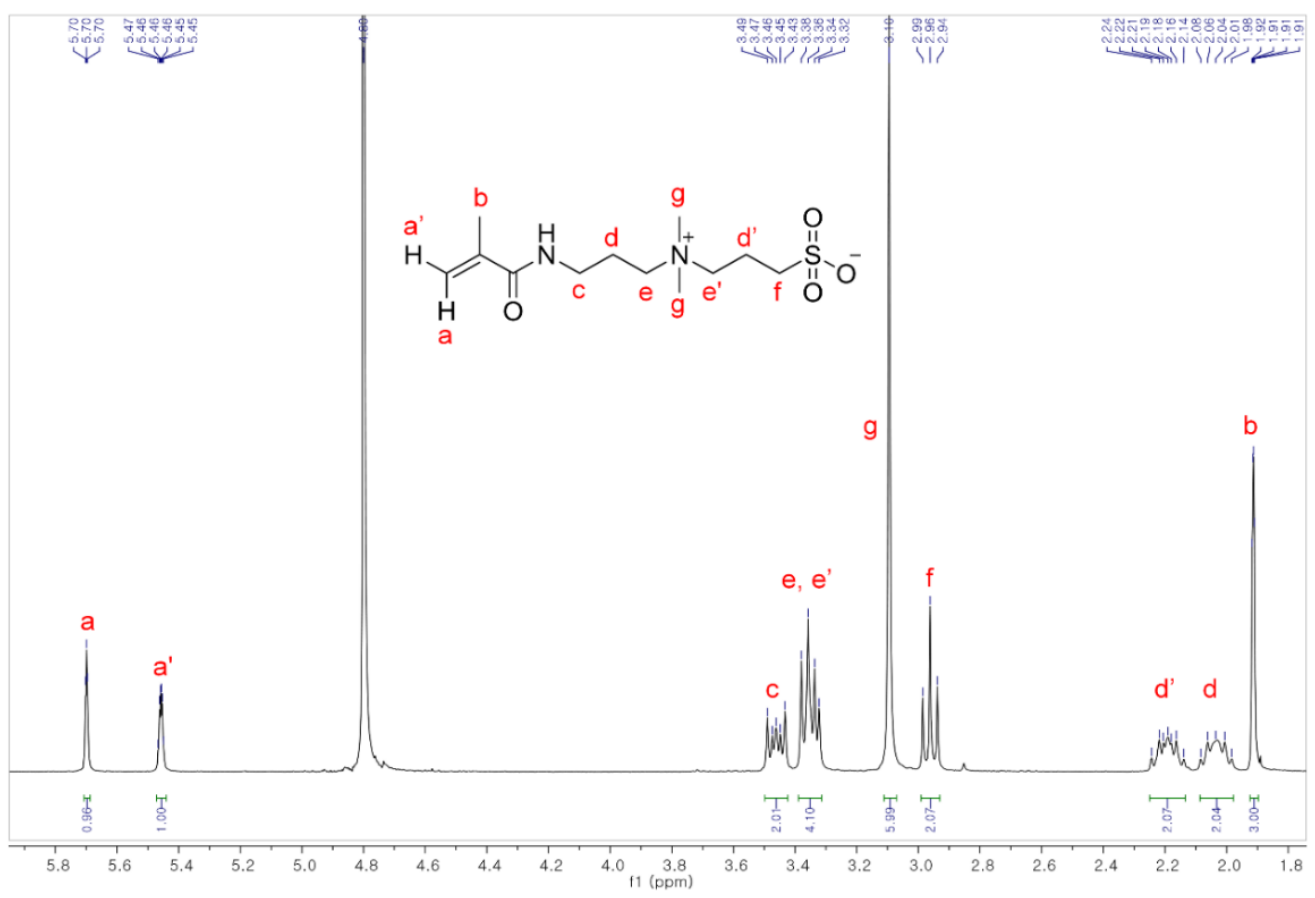

Figure S1. ${ }^{1} \mathrm{H}$ NMR spectrum of MPDSAH in $\mathrm{D}_{2} \mathrm{O}$.

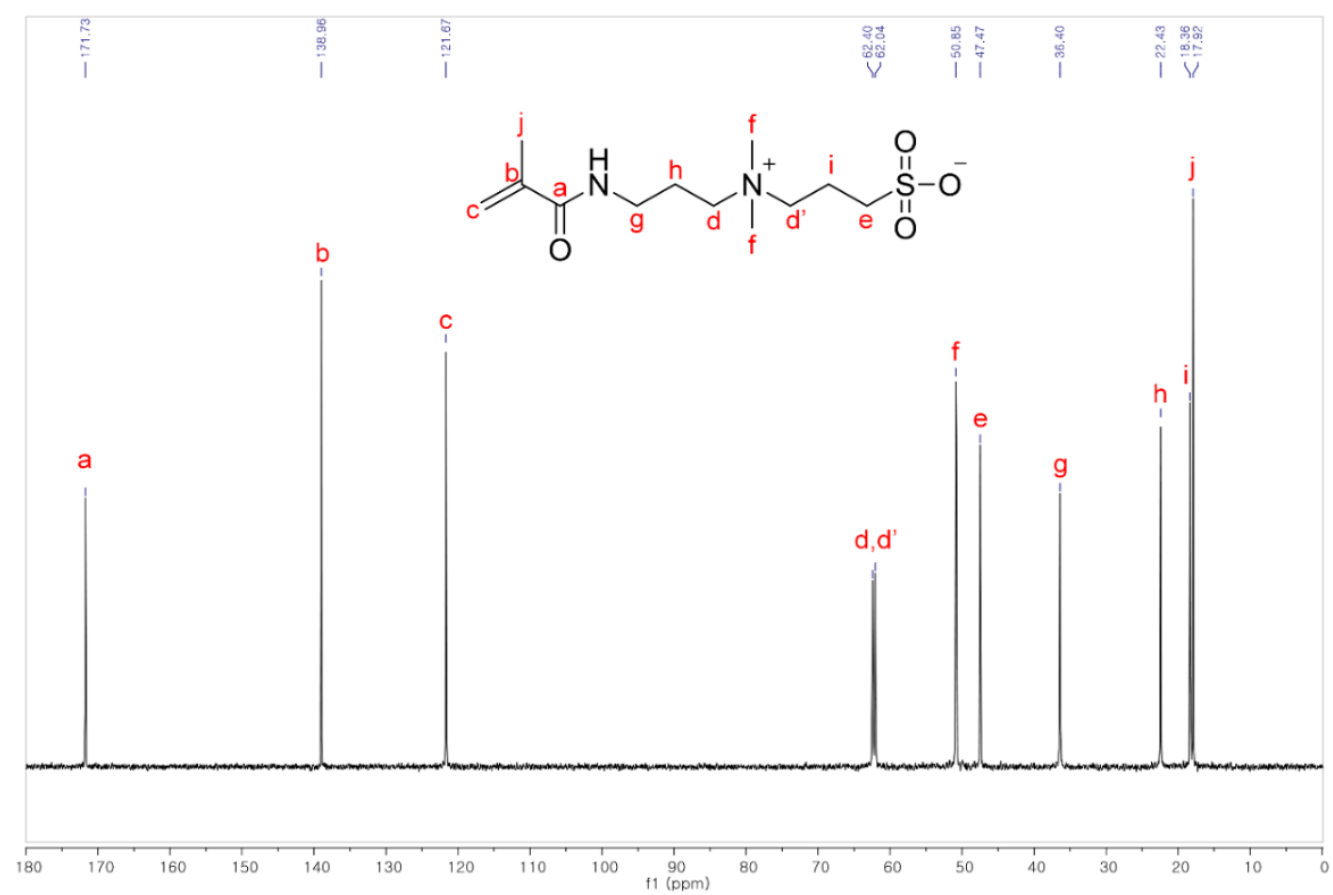

Figure S2. ${ }^{13} \mathrm{C}$ NMR spectrum of MPDSAH in $\mathrm{D}_{2} \mathrm{O}$. 


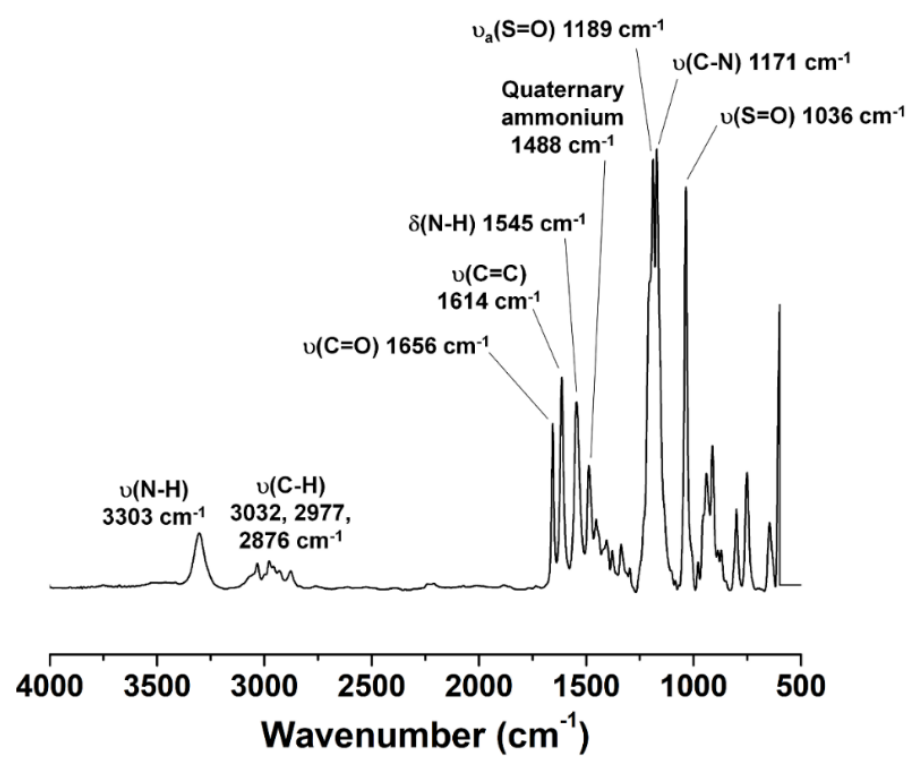

Figure S3. ATR FT-IR spectrum of MPDSAH.

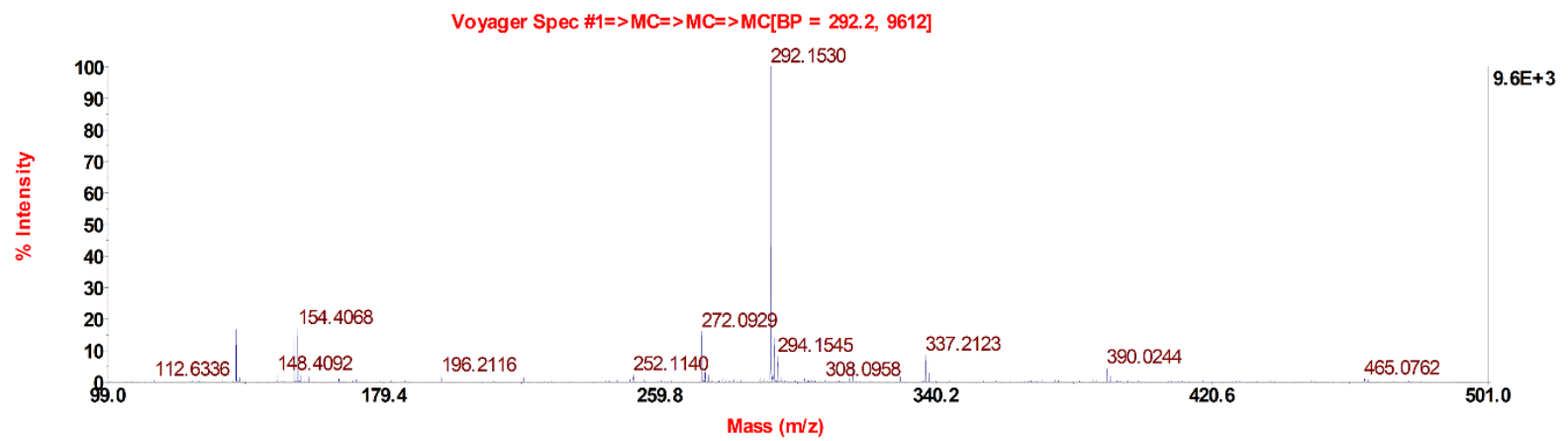

Figure S4. MALDI-TOF mass spectrum of MPDSAH. 


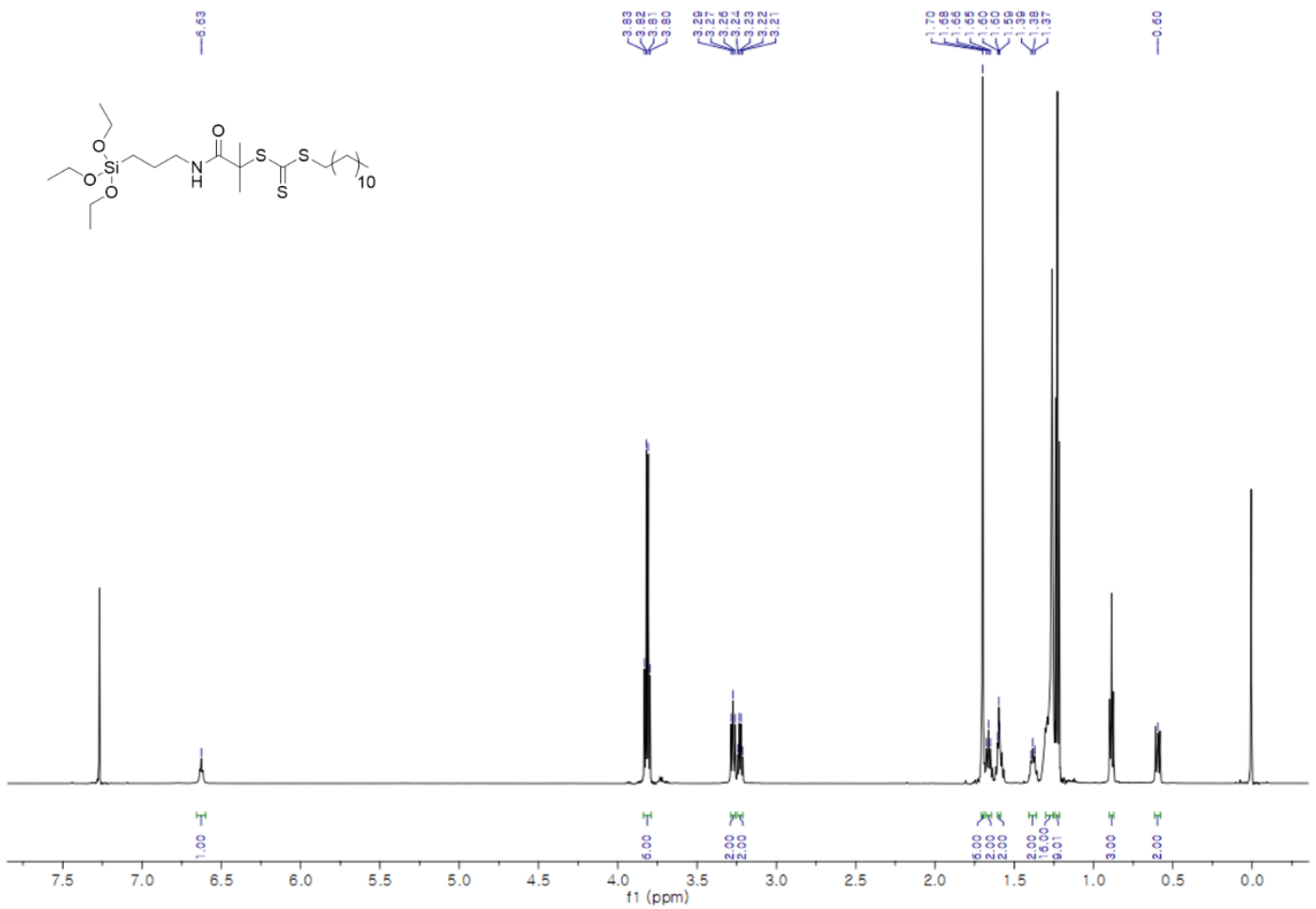

Figure S5. ${ }^{1} \mathrm{H}$ NMR spectrum of DDMAT-derived CTA in $\mathrm{CDCl}_{3}$. 


\section{Polymer brush thickness vs. conversion vs. molecular weight.}

To explore the relationships among polymer brush thickness, conversion, and molecular weight during polymerization, we added sacrificial RAFT agents during $\mathrm{O}_{2}$-SI-RAFT polymerization. These produced free polymer chains in solution, serving as references for those on the surface. ${ }^{3}$ The approach may be flawed because the reaction conditions required for free polymer formation are not necessarily identical to those for polymerization directly onto a surface. Nonetheless, it is often assumed that the two polymer populations (polymer brushes growing on a surface and free polymers in solution) are of the same molecular weight and similar in terms of polydispersity; thus, the molecular weight can be estimated. ${ }^{3}$ As shown in Figure S6, the thicknesses of grafted PEA films increased with both the monomer conversion and the molecular weight of "free" polymers. Also, the molecular weight distributions of "free" polymers in solution were very narrow; all dispersity values were lower than 1.18. Thus, grafting of PEA onto the Si surface was wellcontrolled.

\section{Experimental procedures for conversion and molecular weight determination.}

A silicon substrate functionalized with DDMAT-derived CTA was placed in a $20-\mathrm{mL}$ septa vial in a glovebox filled with $\mathrm{N}_{2}$ gas. After the vial was capped and wrapped in Teflon tape, it was taken out of the glovebox and placed in a fume hood. A solution of EA (0.28 mmol, $80 \mathrm{eq})$ and free CTA (DDMAT, 0.0070 mmol, 2 eq) dissolved in $0.14 \mathrm{~mL}$ DMSO was transferred onto the silicon substrate, and the vial was then exposed to ambient air via a needle inserted through the vial cap. After $2 \mathrm{~min}, \mathrm{Et}_{3} \mathrm{~B}(3.5 \mu \mathrm{L}, 0.0035 \mathrm{mmol}$, 1 eq) was injected onto the silicon substrate using a micropipette. Subsequently, the silicon substrate was left for a certain period. After polymerization, the solution above the wafer was collected and monomer conversion was determined via ${ }^{1} \mathrm{H}$ NMR using maleic acid as the internal standard $\left(0.020 \mathrm{mmol}\right.$ in $\mathrm{D}_{2} \mathrm{O} 0.6$ $\mathrm{mL}$ ); the molecular weight of free polymer was measured via gel permeation chromatography (GPC). The substrate was rinsed with DMSO and water and dried under a stream of argon gas before measuring the thickness of the polymer brushes using the ellipsometer. 

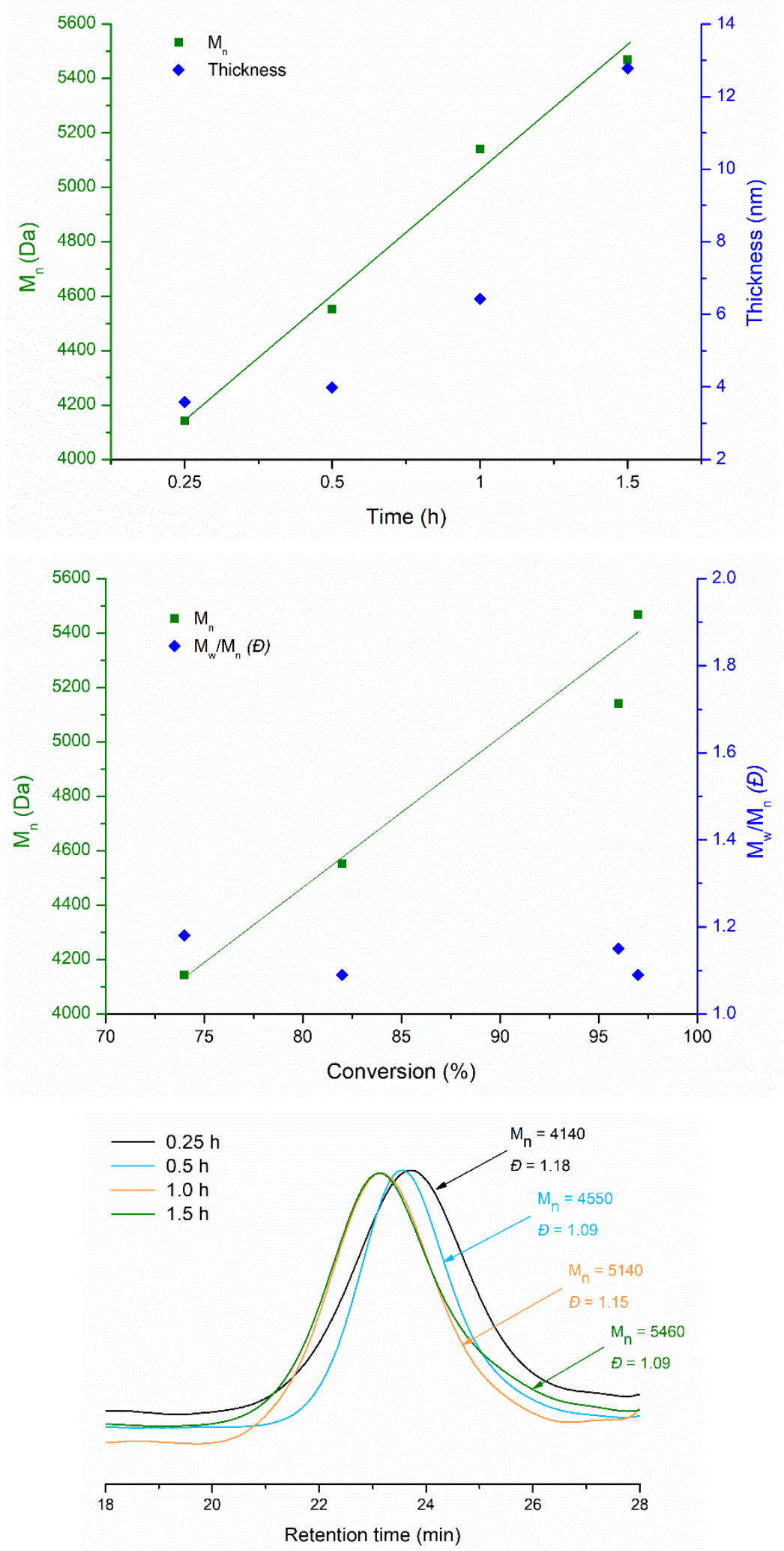

Figure S6. Thickness of the PEA layer versus monomer conversion and molecular weight of "free" polymer with added "free" initiator. 
Table S1. Control experiments. ${ }^{a}$

\begin{tabular}{|c|c|c|c|c|}
\hline Entry & Monomer & Initiator & Atmosphere condition & Thickness (nm) $^{\boldsymbol{b}}$ \\
\hline $\mathrm{C} 1$ & $\mathrm{MPDSAH}$ & $\mathrm{Et}_{3} \mathrm{~B}$ & $\mathrm{O}_{2}$ diffusion & $18.3 \pm 3.78$ \\
\hline $\mathrm{C} 2$ & $\mathrm{MPDSAH}$ & $\mathrm{Et}_{3} \mathrm{~B}$ & Under $\mathrm{N}_{2}$ & $3.0 \pm 1.35$ \\
\hline $\mathrm{C} 3$ & $\mathrm{MPDSAH}$ & - & $\mathrm{O}_{2}$ diffusion & $0.63 \pm 0.31$ \\
\hline
\end{tabular}

${ }^{a}$ Reaction conditions: $[\mathrm{M}]_{0}=1.78 \mathrm{M}$ (in DMSO/water cosolvent), $[\mathrm{M}]_{0}: \mathrm{Et}_{3} \mathrm{~B}=71: 1,2$ h. ${ }^{b}$ Measured by an ellipsometer.

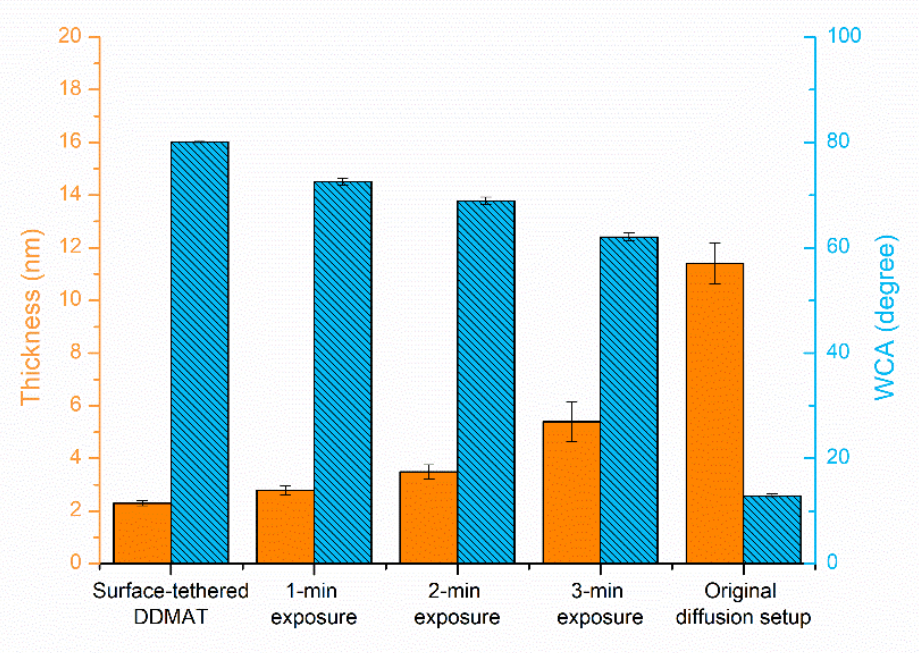

Figure S7. Control experiments with limited $\mathrm{O}_{2}$ exposure. 
Entry 2

poly(HEMA)



Entry 5

poly(DEAEMA)

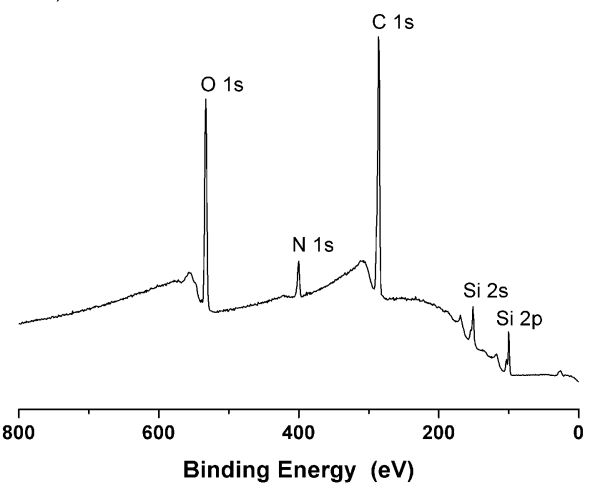

Entry 8

poly(AMA)



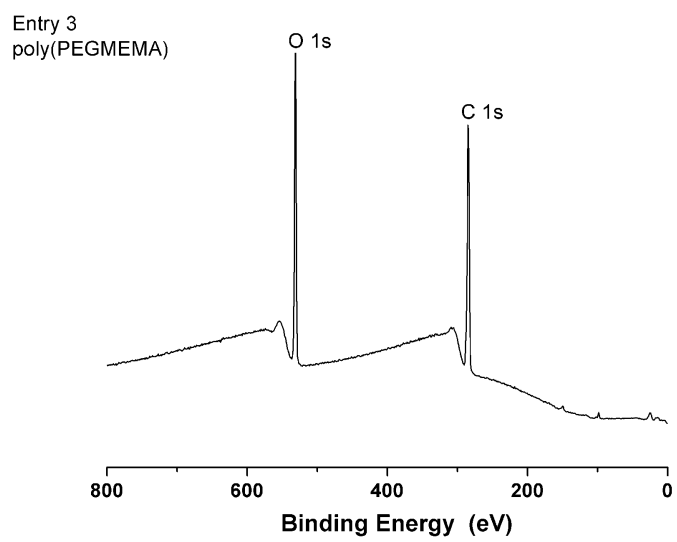

Entry 7

poly(EA)

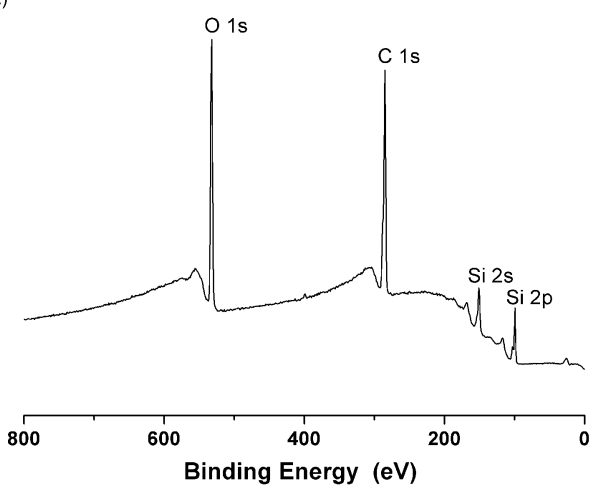

Entry 9

poly(MAA)

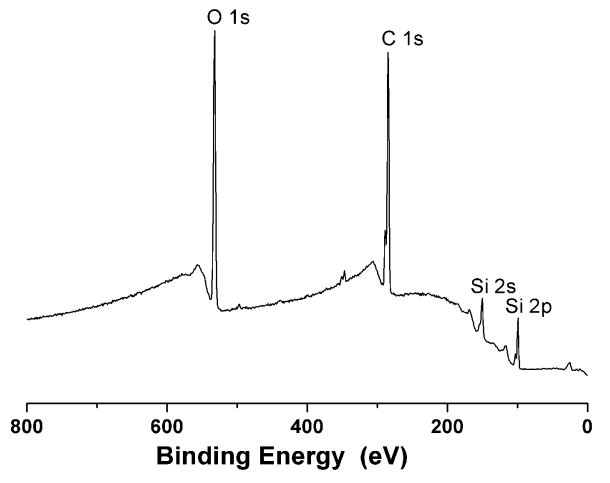

Figure S8. XPS spectra of the various polymer-coated substrates. 


\section{References}

(1) Lange, S. C.; van Andel, E.; Smulders, M. M. J.; Zuilhof, H., Efficient and Tunable ThreeDimensional Functionalization of Fully Zwitterionic Antifouling Surface Coatings. Langmuir 2016, 32, 10199-10205.

(2) Li, M.; Fromel, M.; Ranaweera, D.; Rocha, S.; Boyer, C.; Pester, C. W., SI-PET-RAFT: SurfaceInitiated Photoinduced Electron Transfer-Reversible Addition-Fragmentation Chain Transfer Polymerization. ACS Macro Lett. 2019, 8, 374-380.

(3) Chen, R.; Zhu, S.; Maclaughlin, S., Grafting Acrylic Polymers from Flat Nickel and Copper Surfaces by Surface-Initiated Atom Transfer Radical Polymerization. Langmuir 2008, 24, 6889-6896. 